Article

\title{
Numerical Solution of Axisymmetric Inverse Heat Conduction Problem by the Trefftz Method
}

\author{
Sylwia Hożejowska ${ }^{1, *}$ and Magdalena Piasecka ${ }^{2}$ \\ 1 Faculty of Management and Computer Modelling, Kielce University of Technology, 25-314 Kielce, Poland \\ 2 Faculty of Mechatronics and Mechanical Engineering, Kielce University of Technology, 25-314 Kielce, Poland; \\ tmpmj@tu.kielce.pl \\ * Correspondence: ztpsf@tu.kielce.pl; Tel.: +48-41-34-24-394
}

Received: 21 November 2019; Accepted: 5 February 2020; Published: 6 February 2020

check for updates

\begin{abstract}
In this paper, the issue of flow boiling heat transfer in an annular minigap was discussed. The main aim of the paper was determining the boiling heat transfer coefficient at the HFE-649 fluid-heater contact during flow along an annular minigap. The essential element of the experimental stand was a test section vertically oriented with the minigap $2 \mathrm{~mm}$ wide. Thermocouples were used to measure the temperature of the heater and fluid at the inlet and the outlet to the minigap. The mathematical model assumed that the fluid flow was laminar and the steady-state heat transfer process was axisymmetric. The temperatures of the heated surface and of the flowing fluid were assumed to fulfill energy equations with adequate boundary conditions. The problem was solved by the Trefftz method. The local heat transfer coefficients at the fluid-test surface interface were calculated due to the third kind boundary condition at the saturated boiling. Graphs were used to illustrate: the measurement of the heater surface temperature, 2D temperature distributions in the pipe and fluid, and the heat transfer coefficient as a function of the distance from the minigap inlet. The measurement uncertainties and accuracy of the heat transfer coefficient determination were estimated.
\end{abstract}

Keywords: annular minigap; flow boiling; heat transfer coefficient; inverse problem; Trefftz method

\section{Introduction}

Stricter energy performance requirements combined with the continuing trend towards miniaturization have made thermal management a key issue in engineering research. As a result, increasingly advanced methods are employed to intensify heat transfer processes. Phase change heat transfer is known to raise the efficacy of the process. With the growth of micro-electromechanical systems (MEMS), the development of compact evaporators is becoming crucial. Compact heat exchangers of different constructions and minigap geometries can be used in many applications. The miniaturized systems are being progressively applied in the electronics, medical, automotive, aerospace, and spacecraft industries, as well as in the military sector, power, and nuclear industries and chemical engineering. The development of mini- and microgaps compact heat exchangers, miniature pumps, minicompressors, mini- and micro-turbines and heat pipes, residential air conditioning systems, refrigeration systems, and other thermal systems have become essentialin heat transfer applications. Some proposals for applications of compact heat exchangers with rectangular minichannels in engineering devices were presented in [1]. The prototype heat exchanger used in our research, as well as the heat exchangers with rectangular minichannels tested in our laboratory, are planned to be used for cooling elements of solar systems. A review and future applications for a new generation of high-temperature solar receivers, including well-established devices used in the market and designs tested in laboratories, were described in [2]. 
The results of boiling heat transfer during fluid flow in an annular minigap geometry were analyzed, e.g., in [3-6]. In Reference [3], the experimental investigations on boiling heat transfer during $n$-hexane flow inannular gaps were discussed. The three directly electrically heated test sections with the shapes of geometrically similar annular gaps of different widths $(0.5,1.0$, and $1.5 \mathrm{~mm})$ were used. Infrared thermography was applied to the analysis of the axial wall temperature profile. By solving the stationary one-dimensional heat conduction problem with a source using Fourier's equation, the inside wall temperature was calculated, which allowed for a local heat transfer coefficient determination. The results were mainly illustrated as the heat transfer coefficient in function of vapor quality. Experimental results were presented up to the vapor quality of 0.7 for mass fluxes of up to $700 \mathrm{~kg} /\left(\mathrm{m}^{2} \mathrm{~s}\right)$ and heat fluxes from 30 to $190 \mathrm{~kW} / \mathrm{m}^{2}$ at an outlet pressure of about $0.1 \mathrm{MPa}$. The results show an increase in heat transfer coefficients for higher heat fluxes and smaller gap widths at small values of vapor quality. For larger vapor qualities, the trend for the gap of the $0.5 \mathrm{~mm}$ width was reversed, showing a falling heat transfer coefficient with increasing heat fluxes. The mass flux gained higher influence on the heat transfer coefficient at higher vapor qualities. Flow boiling heat transfer of R-134a in an annular duct was the subject of Reference [4]. Experiments were carried out to investigate the subcooled flow boiling heat transfer and visualize the associated bubble characteristics. A horizontal annular duct had an inside diameter of $6.35 \mathrm{~mm}$ and outside diameter of $16.66 \mathrm{~mm}$. The effects of the imposed wall heat flux, mass flux, liquid subcooling, and saturation temperature on the resulting nucleate boiling heat transfer and bubble characteristics were examined. In the experiment, nucleation hysteresis was noted in the boiling curves during the onset of nucleate boiling (ONB), especially at low saturation temperatures and high subcooling. Effects of various parameters on the hysteresis were examined. An increase in the subcooling resulted in an intensified heat transfer. The boiling heat transfer was slightly higher for a lower saturation temperature and was little affected by the mass flux. Flow visualization of the boiling processes revealed that the bubble generation frequency was suppressed by raising the mass flux and liquid subcooling. Finally, empirical correlations for the heat transfer coefficient and bubble departure diameter in the subcooled flow boiling of R-134a were proposed. The authors of References [5,6] focused on subcooled [5] and saturated flow boiling heat transfers [4] of R-407C and associated bubble characteristics in a horizontal narrow annular duct. The experiments were concerned on the impact of the channel size on the saturated flow boiling heat transfer and associated bubble characteristics. The gap of the duct was fixed at 1.0 and $2.0 \mathrm{~mm}$. It was observed that the saturated flow boiling heat transfer coefficient increased with a decrease in the duct gap [5]. The authors stated that the effects of the mass flux and saturated temperature on this coefficient were slighter in both boiling regions $[5,6]$. The results from the flow visualization showed that the mean diameter of the bubbles departing from the heated surface decreased at increasing mass flux. The bubble departure frequency increased at reducing duct sizes. The constructed boiling curves indicated that the temperature overshoot at ONB was relatively significant for the subcooled flow boiling of R-407C in the duct [6]. Besides, the subcooled flow boiling heat transfer coefficient increased with a reduction in the duct gap but decreased with an increase in the inlet liquid subcooling. Moreover, raising the heat flux imposed on the duct can cause a significant increase in the boiling heat transfer coefficients [5,6]. In Reference [5], the comparison of the collected heat transfer data for R-407C with R-134a for the same duct and with some existing correlations was also provided. Furthermore, the correlations for the R-407C flow boiling heat transfer data were proposedin [5,6].

Several recent authors' papers have been published to address the issues of heat transfer in flow boiling in annular minigaps of the same dimensions as presented in this work [7-10] and minichannels of rectangular cross-sections, like in [11-16]. The aim of Reference [7] was to present mathematical models of heat transfer in flow boiling in a 1-3-mm-wide minigap. The one- and two-dimensional mathematical models were proposed to describe stationary heat transfer in the gap. No experimental data was shown. The two one-dimensional mathematical approaches of boiling heat transfer coefficients during flow in a minigap were proposed in Reference [8]. There were considered two ways of describing layers in a measurement module with a cylindrical annulus minigap. In the 
first approach, the measurement module was presented as a planar multilayer wall and, in the second approach, as a multilayer cylindrical wall. The values of the local heat transfer coefficients determined from two approaches were compared. The first results from an experiment with distilled water as the working fluid were shown. Both approaches gave similar results. The results from experiments with HFE-649 flowing in an annular minigap were illustrated in [9]. This gap of a $1 \mathrm{~mm}$ width was created between the metal pipe with an enhanced surface contacting fluid and the external glass pipe. The local values of the heat transfer coefficient for stationary state conditions were calculated using one-dimensional methods in which the multilayer cylindrical wall was assumed to be planar. The results were presented as a function of the heat transfer coefficient along the minigap length and as boiling curves, prepared for selected values of mass flow rates and five types of the enhanced heated surfaces and a smooth one. The observations indicated that the highest local values of the heat transfer coefficient were obtained with using the enhanced surface produced by the electromachining process (spark erosion) at the saturated boiling region. The boiling curves generated for two distances from the minigap inlet have similar plots without a drop in the temperature of the heated surface characteristics for nucleation hysteresis. One of the key parameters affecting boiling heat transfer is development of a heated surface that can be produced by different technologies, as described in [1,17-19]. Reference [10] described a two-dimensional mathematical model of heat transfer in flow boiling of HFE-7100 in a minigap. The Fourier transform and the Trefftz method were used for identification of temperature distributions of heated surfaces and, furthermore, the local heat transfer coefficient. It was underlined that its values obtained from the Fourier transform and from the Trefftz method were similar.

This paper reports the results of research and discusses the mathematical method used in the calculations. The test stand includes a test section with a minigap with annular cross-section. The experiments were carried out in stationary conditions. The temperature of the metal surface near the heater was measured with thermocouples. The aim of the experiments was to collect data which, with the proposed mathematical model and computational method, enabled determination of local heat transfer coefficients at the interface between the heated surface and the boiling liquid flowing through a minigap. The specificity of the test section construction as well as the physics of the problem under consideration make it impossible to directly measure the required quantities (temperature of the heated wall and its gradient, fluid temperature) in order to determine the local heat transfer coefficients.

The proposed system of two energy equations in the heater and flowing fluid together with an adequate set of boundary conditions leads to the solution of the conjugated inverse and direct heat conduction problems [20]. Inverse heat conduction problems (IHCPs) like those presented, e.g., in [21-27], belong to ill-posed problems [28] and require effective and stable solution methods. The Trefftz method [29] complies with this requirement, even when not all boundary conditions are fully known [30-35]. In the Trefftz method, the unknown solution of a partial differential equation is approximated by a linear combination of the Trefftz functions (called T-functions) that satisfy the governing equation exactly. A novel idea, presented in this paper, was to apply the Trefftz method to the simultaneous determination of the two-dimensional temperature fields: in the heated surface and fluid flowing through the minigap. It is also worth noting that both the mathematical model and numerical calculations are based on real experimental data. Two sets of the T-functions (for the Laplace equation and the energy equation for fluid) were used to compute the temperature distributions in the heater and the boiling fluid. The computation yields a continuous function representing the heater temperature in the whole domain. It allows to determine its gradient on the boundary of the domain and, consequently, based on the third kind boundary condition, also the values of the local heat transfer coefficients at the fluid-heater contact.

\section{Experimental Data}

We would like to emphasize that the results presented in the next sections are based on the data collected from the research conducted on our own experimental stand. Providing calculations on the 
basis of experimental data is essential for the reliable prediction of heat transfer in complicated heat transfer systems, in which the sizes of bubbles can be larger than the size of a channel.

The experimental stand comprises: the flow loop with a test section in which the working fluid circulates (HFE-649, 3M), the data and image acquisition system, and the power supply and control system (Figure 1). The test section with an annular minigap vertically oriented, Figure 2, is the main element of the circulated flow loop.

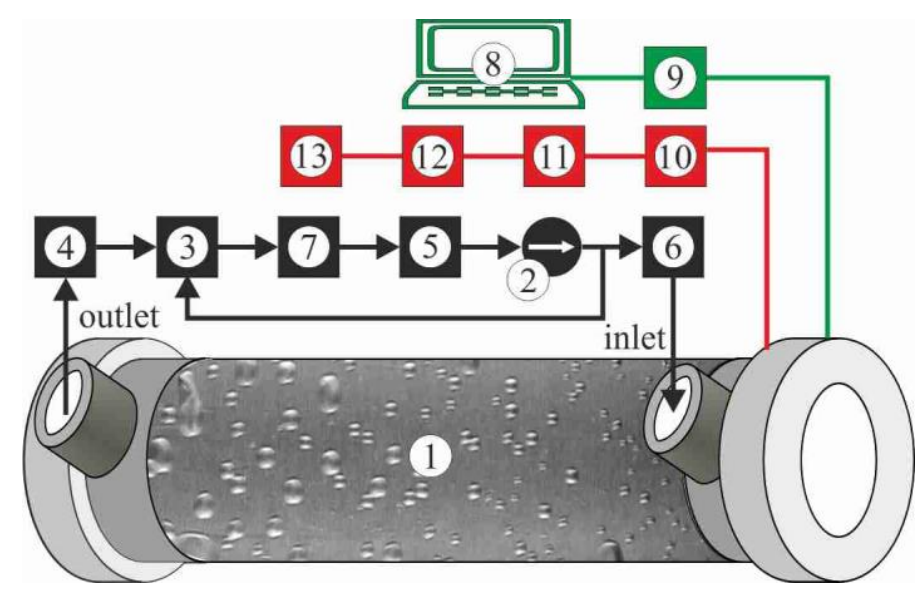

Figure 1. The schematic diagram of main loops realized in the experimental stand: 1 -a test section, 2-a gear pump, 3-a compensating tank, 4-a tube-type heat exchanger, 5-a filter, 6-a mass flow meter, 7-a deaerator, 8-a data acquisition station, 9-a pc computer, 10-an ammeter, 11-a voltmeter, 12-an inverter welder, and 13-a shunt.

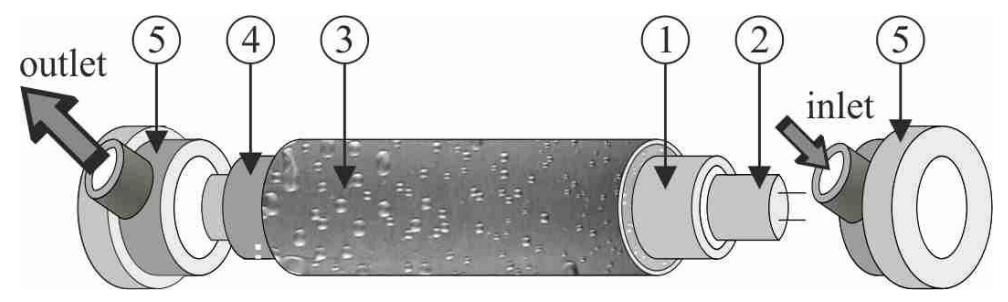

Figure 2. The schematic diagram of the test section: 1-an annular minigap, 2-a cartridge heater, 3-a glass pipe, 4-a copper pipe, and 5-a test section header.

The gap of 2-mm-wide and 180-mm-long was formed between the external glass pipe and the enhanced surface of the copper pipe positioned along the same axis, similarly as to the cartridge heater located inside this pipe. The heater is powered by an autotransformer with adjusted current intensity. The fluid temperature and pressure are measured at the inlet and the outlet to the minigap. K-type thermocouples are used for temperature measurement. Thermocouples were also placed in the gap between the copper pipe and the heater in the thermal paste. These 18 thermocouples were fixed evenly, with a spacing of $10 \mathrm{~mm}$ in the flow line according to the pitch.

During the experimental series, there was a gradual increase in the electric power supplied to the cartridge heater at steady-state experiment conditions.

\section{Mathematical Model}

In the mathematical model, the test section was modeled as concentric cylindrical layers (Figure 3) with stationary and temperature-independent thermal properties. Neglecting both the thin thermal conductive filler $\left(\sim 10^{-4} \mathrm{~m}\right)$ and the thermocouple size, it was assumed that the surface of the copper pipe surface has direct contact with the heater surface. Furthermore, it was assumed that the heat transfer in the test section and the minigap is axisymmetric; i.e., the temperature distributions in the 
elements of the module depend on only two variables: $r$, referring to the thickness of the cartridge heater $\left(r_{1}\right)$ and the copper pipe $\left(r_{2}-r_{1}\right)$ and the width of the minigap $\left(r_{3}-r_{2}\right)$ and $z$ (along the flow direction) $[7,10]$.

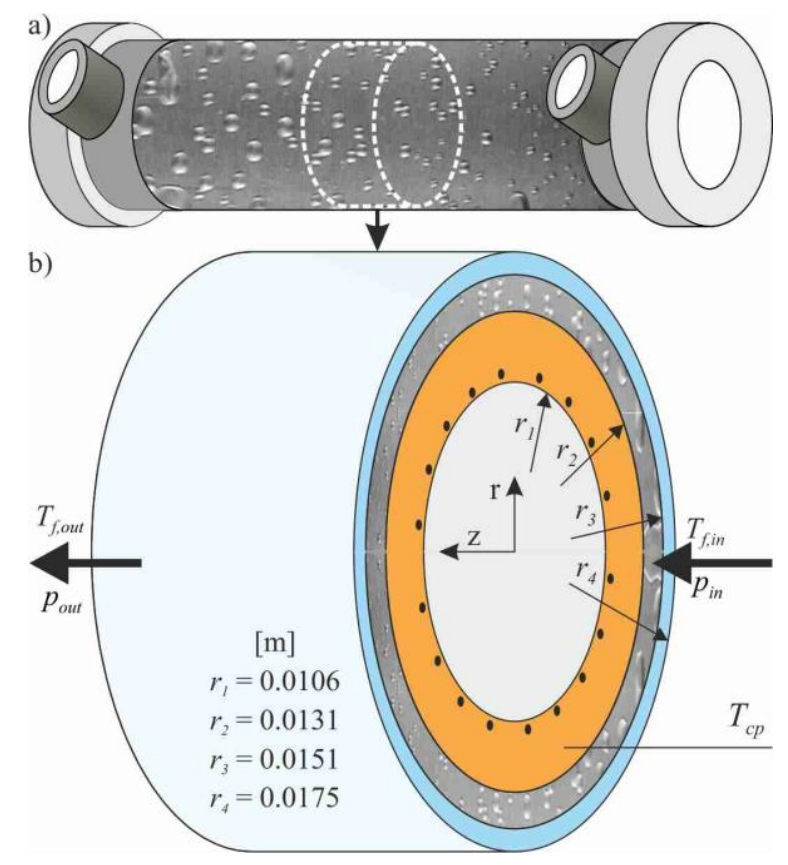

Figure 3. The schemes of the test section: (a) a general view and (b) a cross-section with marked layers used in the mathematical model.

The following additional assumptions considering the fluid flow were made: (i) the flow is in steady-state and laminar (Reynolds number $<2100$ ) with only one nonzero velocity component $v_{\text {ave }}$ parallel to the flow direction, (ii) the flow is nonadiabatic and has a constant cross-section, (iii) the temperature of the fluid at the inlet $T_{f, \text { in }}$ and outlet $T_{f, \text { out }}$ of the minigap is known, and (iv) the gravitational force is out of consideration.

The temperature distributions of the copper pipe and of the fluid were obtained from the solution of the Laplace equation and of the energy equations:

-for the copper pipe:

$$
\frac{1}{r} \frac{\partial}{\partial r}\left(r \frac{\partial T_{c p}}{\partial r}\right)+\frac{\partial^{2} T_{c p}}{\partial z^{2}}=0
$$

-for the fluid:

$$
\frac{1}{r} \frac{\partial}{\partial r}\left(r \frac{\partial T_{f}}{\partial r}\right)+\frac{\partial^{2} T_{f}}{\partial z^{2}}=\frac{v_{a v e}}{a} \frac{\partial T_{f}}{\partial z}
$$

where $a=\frac{k_{f}}{c_{p, f} \rho_{f}}$ and $v_{\text {ave }}$ is equal to the average fluid velocity in the minigap.

Boundary conditions (3) and (4) were derived from the knowledge of measurements of the heating surface temperature and current $I$ and voltage drop $\Delta U$ supplied to the heater:

$$
\begin{gathered}
k_{c p} \frac{\partial T_{c p}}{\partial r}=\frac{I \cdot \Delta U}{2 \pi r_{1} L}=q^{\prime \prime} \text { for } r=r_{1} \\
T_{c p}\left(r_{1}, z\right)=T_{\text {approx }}(z) \text { at } 0 \leq z \leq L
\end{gathered}
$$


where the measurements of copper pipe temperature were approximated by a polynomial $T_{a p p r o x}(z)$. Since the length of the pipe significantly exceeds its width, we can assume that its walls for $z=0$ and $z$ $=L$ are isolated:

$$
\frac{\partial T_{c p}}{\partial z}=0 \text { for }(\mathrm{a}) z=0 \text { and }(\mathrm{b}) z=L
$$

For Equation (2), we assumed that the temperature of the fluid both at the minigap inlet $\left(T_{f, i n}\right)$ and outlet $\left(T_{f, o u t}\right)$ is known, i.e.,

$$
\begin{gathered}
T_{f}(r, 0)=T_{f, \text { in }} \text { for } r_{1} \leq r \leq r_{2} \\
T_{f}(r, L)=T_{f, \text { out }} \text { for } r_{1} \leq r \leq r_{2}
\end{gathered}
$$

and for $0 \leq z \leq L$ at the fluid-copper pipe interface, the fluid temperature fulfills the condition

$$
T_{f}\left(r_{2}, z\right)=T_{\text {sat }}(z)
$$

In condition (8), the saturation temperature of the fluid $T_{\text {sat }}$ is a function of a pressure that changes linearly from the inlet to the outlet of the minigap.

Additionally, neglecting the heat exchange with the environment at the fluid-external glass pipe interfaces, it was assumed that the outer wall ofthe minigap was isolated:

$$
\frac{\partial T_{f}\left(r_{3}, z\right)}{\partial r}=0 \text { for } 0 \leq z \leq L
$$

Knowledge of functions describing the temperature distribution of the copper pipe and flowing fluid allows to determine the local value of the heat transfer coefficient at the copper pipe-fluid contact from the third kind boundary condition:

$$
h_{2 D}(z)=\frac{-\frac{k_{c p}}{L} \int_{0}^{L} \frac{\partial T_{c p}}{\partial r}\left(r_{2}, z\right) d z}{T_{c p}\left(r_{2}, z\right)-T_{f, a v e}(z)}
$$

The reference fluid temperature $T_{f, a v e}$ is calculated as an average fluid temperature in the minigap, i.e.,

$$
T_{f, a v e}(z)=\frac{0.5}{r_{3}-r_{2}} \int_{r_{2}}^{r_{3}} T_{f}(r, z) d r
$$

\section{Numerical Method}

The solution of the presented IHCP leads to solving three inverse problems of determining: (i) the temperature; (ii) the heat flux; and (iii) the thermal properties of a material (heat transfer coefficient, in this case). These are ill-posed problems which require effective and stable methods of solution. In this paper, the Trefftz method was applied to determine the two-dimensional temperature distributions, both of the copper pipe and the flowing fluid. The unknown temperature $T_{c p}$ was approximated by a linear combination of two types of the T-functions $f_{n, 0}(r, z)$ and $g_{n}(r, z)$ appropriate for Laplace Equation (1), i.e.,

$$
T_{c p}(r, z)=\sum_{n=0}^{N_{c p}} a_{n} f_{n, 0}(r, z)+\sum_{m=0}^{M_{c p}} b_{m} g_{m}(r, z)
$$

The method for deriving T-functions for Equation (1) was described in detail in [10]. The recursive formulas of T-functions $f_{n, 0}(r, z)$ and $g_{n}(r, z)$,as well as their properties, are listed in Table 1. 
Table 1. Properties of T-functions $f_{n, 0}(r, z)$ and $g_{n}(r, z)$.

\begin{tabular}{|c|c|}
\hline Functions $f_{n, 0}(r, z)$ & Functions $g_{n}(r, z)$ \\
\hline \multicolumn{2}{|c|}{ satisfy the Laplace Equation (1) } \\
\hline \multicolumn{2}{|c|}{ recursive formulas for functions: } \\
\hline $\begin{array}{c}f_{0,0}=1, f_{1,0}=z \\
\text { and for } n \geq 2 \\
f_{n, 0}=z \frac{2 n-1}{n^{2}} f_{n-1,0}-\frac{\left(r^{2}+z^{2}\right)}{n^{2}} f_{n-2,0}\end{array}$ & $\begin{array}{c}g_{0}=\ln r, g_{1}=z \ln r, \\
\text { and for } n \geq 2 \\
g_{n}=z \frac{2 n-1}{n^{2}} g_{n-1}-\frac{r^{2}+z^{2}}{n^{2}} g_{n-2}+\frac{2}{n^{2}} r \frac{\partial f_{n, 0}}{\partial r}\end{array}$ \\
\hline $\begin{array}{r}\text { recursive fo } \\
r \frac{\partial f_{0,0}}{\partial r}=0, \frac{\partial f_{0,0}}{\partial z}=0 \\
\text { and for } n \geq 1 \\
r \frac{\partial f_{n, 0}}{\partial r}=n \cdot f_{n, 0}-z \cdot f_{n-1,0} \\
\frac{\partial f_{n, 0}}{\partial z}=f_{n-1,0}\end{array}$ & $\begin{array}{l}\text { for derivatives: } \\
\qquad \begin{array}{l}r \frac{\partial g_{0}}{\partial r}=1, \frac{\partial g_{0}}{\partial z}=0 \\
\quad \text { and for } n \geq 1 \\
r \frac{\partial g_{n}}{\partial r}=f_{n, 0}+n \cdot g_{n}-z \cdot g_{n-1} \\
\quad \frac{\partial g_{n}}{\partial z}=g_{n-1}\end{array}\end{array}$ \\
\hline $\begin{array}{r}\text { the limits when } \\
\lim \left|f_{n, 0}(r, z)\right|=0, \lim \left|\frac{\partial f_{n, 0}}{\partial r}\right|=0\end{array}$ & $\begin{array}{l}\text { at a fixed point }(r, z) \text { : } \\
\qquad \lim \left|g_{n}(r, z)\right|=0, \lim \left|\frac{\partial g_{n}}{\partial r}\right|=0\end{array}$ \\
\hline
\end{tabular}

To calculate the temperature distribution of fluid $T_{f}$ flowing in the annular gap between two fixed concentric cylinders, the T-functions $u_{n}(r, z)$ for Equation (2) were used [7]. The T-functions $u_{n}(r, z)$ are the sums of harmonic polynomials $f_{n, 0}(r, z)$ for the Laplace Equation (1) and polynomials $f_{n, i}(r, z)$ :

$$
u_{n}(r, z)=f_{n, 0}(r, z)+\sum_{i=1}^{n} f_{n, i}(r, z)
$$

The polynomials $f_{n, i}(r, z), i=1,2, \ldots, n$, are defined by formula [7]:

$$
f_{n, i}(r, z)=\frac{v_{\text {ave }}}{a} \Delta^{-1}\left[\frac{\partial f_{n, i-1}}{\partial z}\right]
$$

where the inverse operator $\Delta^{-1}$ for a monomial in the form $r^{n} z^{k}$ is determined as follows [7]:

$$
\Delta^{-1}\left(r^{n} z^{k}\right)=\left\{\begin{array}{c}
\frac{r^{n+2} z^{k}}{(n+2)^{2}} \text { for } k=0,1 \\
\frac{r^{n+2} z^{k}}{(n+2)^{2}}-\frac{k(k-1)}{(n+2)^{2}} \Delta^{-1}\left(r^{n+2} z^{k-2}\right) \text { for } k \geq 2
\end{array}\right.
$$

The fluid temperature $T_{f}$ was approximated in the form

$$
T_{f}(r, z)=\sum_{n=1}^{N_{f}} c_{n} u_{n}(r, z)
$$

as a linear combination of the T-functions $u_{n}(r, z)$.

The unknown coefficients $a_{n}, b_{n}$ in (12) and $c_{n}$ in (16) are determined by minimizing the adequate functionals. For example, the functional allowing to determine coefficients $c_{n}$ has the form

$$
\begin{aligned}
J_{f}= & \int_{r_{2}}^{r_{3}}\left(\sum_{n=1}^{N_{f}} c_{n} u_{n}(r, 0)-T_{f, \text { in }}\right)^{2} d r+\int_{r_{2}}^{r_{3}}\left(\sum_{n=0}^{N_{f}} c_{n} u_{n}(r, L)-T_{f, \text { out }}\right)^{2} d r+ \\
& +\int_{0}^{L}\left(\sum_{n=0}^{N_{f}} c_{n} u_{n}\left(r_{2}, z\right)-T_{f}(z)\right)^{2} d z+\int_{0}^{L}\left(\sum_{n=0}^{N_{f}} c_{n} \frac{\partial u_{n}\left(r_{3}, z\right)}{\partial r}\right)^{2} d z
\end{aligned}
$$

The approximate temperatures $T_{c p}$ and $T_{f}$ obtained by the Trefftz method are the functions which: (i) are continuous, (ii) satisfy Equations (1) and (2) exactly, and (iii) satisfy the adopted boundary conditions approximately. Equation (1) subject to the boundary conditions (3)-(5) and Equation (2) 
with the conditions (6)-(9) define the IHCP in the copper pipe and a direct heat conduction problem in the fluid, respectively.

\section{Results and Discussion}

Based on the model described in the previous section, the Trefftz method was adopted to determine a two-dimensional temperature field for the copper pipe and the flowing fluid. The calculations were performed for five heat flux densities $q^{\prime \prime}$ in the range of $9.24 \div 18.33 \mathrm{~kW} / \mathrm{m}^{2}$. The main experimental parameters from the series taken into account for calculations were those listed in Table 2. Additionally, Table 2 includes the measurement uncertainties. The uncertainty of temperature measurement by K-type thermocouples was assumed, like in [11]. Other uncertainties were estimated according to the data from the manufacturer of the measuring devices.

Table 2. Average values of parameters of the experiment and the uncertainties.

\begin{tabular}{ccc}
\hline Parameter & Average Value & Uncertainty \\
\hline inlet fluid temperature & $293.91 \mathrm{~K}$ & $0.9 \mathrm{~K}$ \\
\hline outletfluid temperature & $321.89 \mathrm{~K}$ & $0.9 \mathrm{~K}$ \\
\hline measurement temperature of the pipe surface & from $352.26 \mathrm{~K}$ to $371.48 \mathrm{~K}$ & $0.9 \mathrm{~K}$ \\
\hline inlet pressure & $177 \mathrm{kPa}$ & $\pm 0.05 \%$ of reading * \\
\hline outlet pressure & $167 \mathrm{kPa}$ & $\pm 0.05 \%$ of reading * \\
\hline mass flow rate & $0.0033 \mathrm{~kg} / \mathrm{s}$ & $\pm 0.10 \%$ of reading \\
\hline voltage drop & $120 \mathrm{~V}$ & $0.001 \Delta \mathrm{U}+0.0001 *$ \\
\hline current & $1.4 \mathrm{~A}$ & $0.1 \mathrm{~A}^{*}$ \\
\hline$*$ according to the data from manufacturer of the measuring device.
\end{tabular}

Figure 4 illustrates the measurement of temperatures of the copper pipe obtained with the use of eighteen K-type thermocouples.

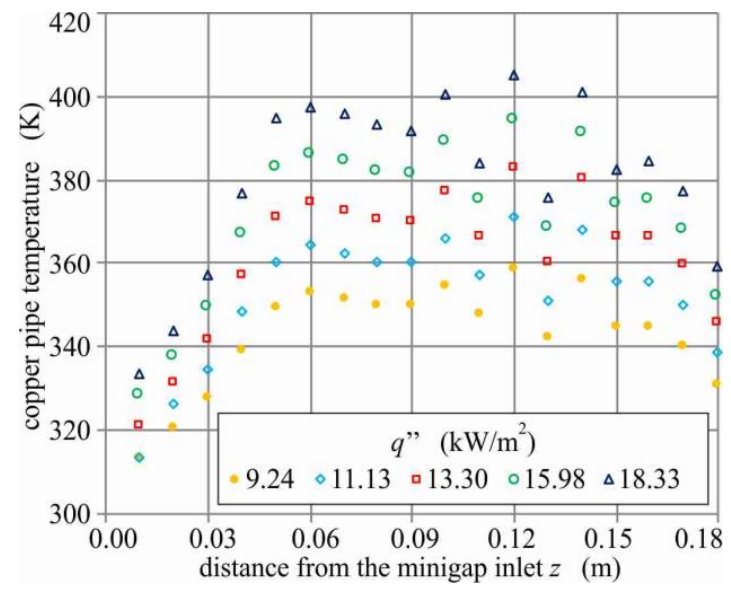

Figure 4. Copper pipe temperature obtained with the use of 18 K-type thermocouples.

In the first step, the temperature distribution of the copper pipe was determined using the Trefftz method utilizing $18 \mathrm{~T}$-functions for Equation (1). Next, five T-functions defined for Equation (2) were used to calculate the fluid temperature. The number of T-functions employed were chosen so that the approximations of the copper pipe temperature $T_{c p}$ and the fluid temperature $T_{f}$ would be polynomials of the same degree. To verify the accuracy with which functions $T_{c p}$ and $T_{f}$ satisfy the adequate boundary conditions, the mean square error (MSE) defined as in [35] was used. The temperature $T_{c p}$ and $T_{f}$ fulfill the boundary conditions with the MSEs, whose average values are listed in Table 3 (only 
representative results). The boundary conditions for which the MSEs have not been shown in Table 3 were satisfied with similar accuracy.

Table 3. Average mean square errors (MSEs) for boundary conditions (6), (8), and (9).

\begin{tabular}{cc}
\hline Boundary Conditions & Average MSE \\
\hline condition (6) & $0.75 \mathrm{~K}$ \\
condition (8) & $167.58 \mathrm{~K}$ \\
condition (9) & $2.5 \times 10^{-3} \mathrm{~W} / \mathrm{m}^{2}$ \\
\hline
\end{tabular}

The 2D temperature distributions of the copper pipe and the flowing fluid are presented in Figure 5.
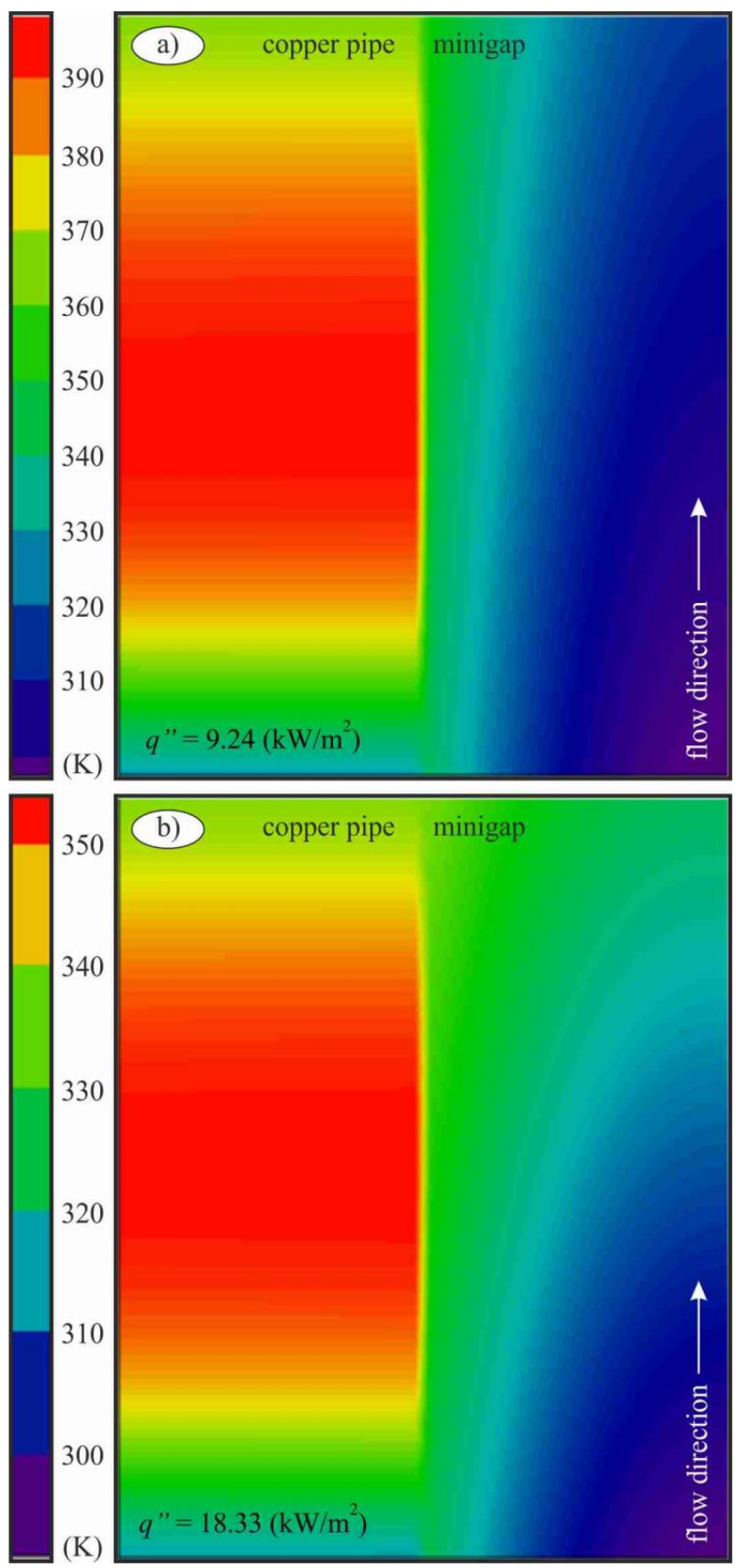

Figure 5. 2D fields of copper pipe temperatures and fluid temperatures obtained by the Trefftz method for: (a) $q^{\prime \prime}=9.24 \mathrm{~kW} / \mathrm{m}^{2}$ and (b) $q^{\prime \prime}=18.33 \mathrm{~kW} / \mathrm{m}^{2}$ (figures are not drawn to scale). 
To verify the results obtained from the proposed mathematical model, the local heat transfer coefficients were computed using a simplified approach where the measurement module was treated as a multilayer cylindrical wall and the heat transfer in the direction perpendicular to the flow was neglected [8]:

$$
h_{1 D}(z)=\frac{q^{\prime \prime}}{T_{\text {approx }}(z)-r_{1} q^{\prime \prime} \frac{\ln \left(r_{2} / r_{1}\right)}{k_{c p}}-T_{\text {sat }}(z)}
$$

Figure 6 compares the heat transfer coefficients (as a function of the distance from the minigap inlet) computed with the Trefftz method, Equation (10), and the simplified approach, Equation (18).
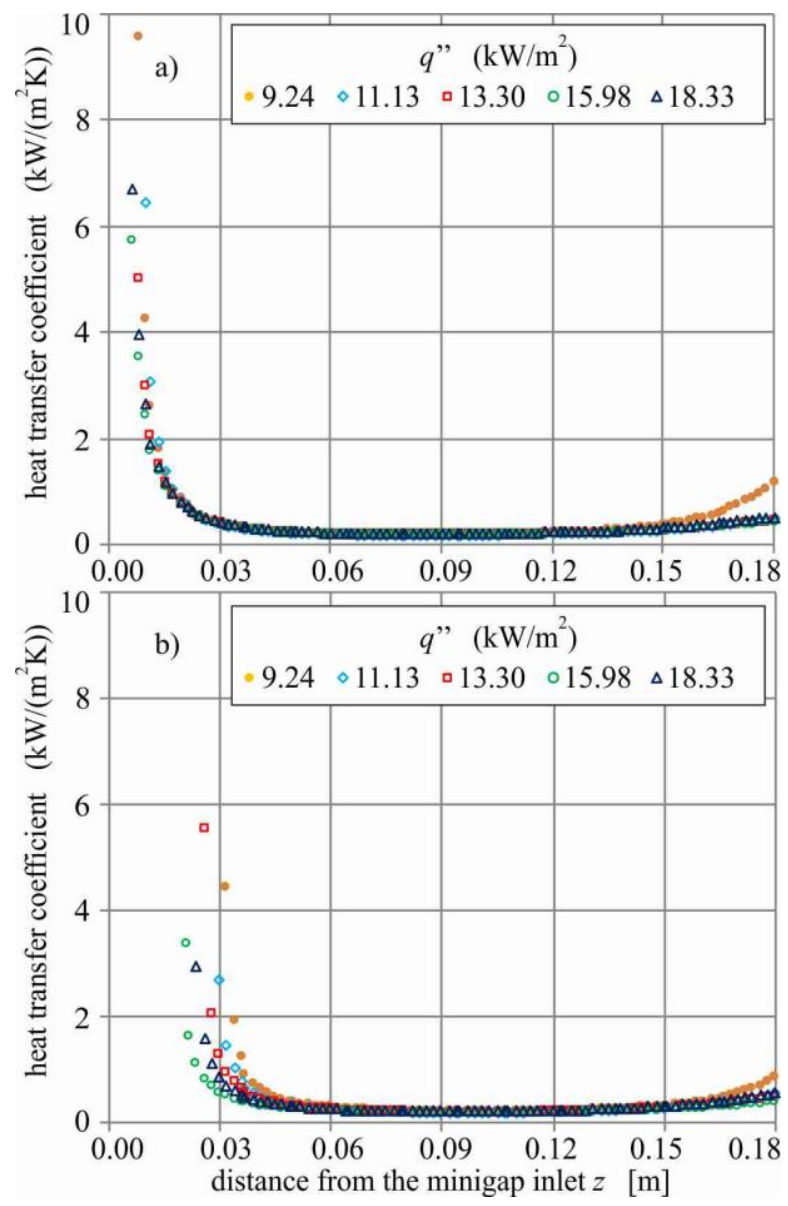

Figure 6. Heat transfer coefficient vs. the distance from the minigap inlet, computed with: (a) formula (10) and (b) formula (18).

When analyzing the results presented in Figure 6, it can be noticed that the heat transfer coefficient decreased along the entire heater length of the minigap, which resulted in an increase in temperature in the heating surface (Figures 4 and 5). Increase of the vapor phase in the flow causes a decrease in values of the heat transfer coefficient. The heat transfer coefficient calculated from Formula (10) takes on slightly higher values than the one calculated from Formula (18). Larger differences between the values of heat transfer coefficients $h_{1 D}$ and $h_{2 D}$ are for lower values of heat fluxes. The maximum relative differences (MRD), determined similarly as in [11], between heat transfer coefficient values computed with Equations (10) and (18) range from to $12.8 \%$ to $36.0 \%$, which indicates that the results obtained by both approaches are consistent.

The mean relative errors (MREs) were calculated for the local heat transfer coefficients, as in [11,31]. Table 4 shows the dependence of the MRE on the heat fluxes $q^{\prime \prime}$ for one- and two-dimensional approaches. 
Table 4. MREsof the local heat transfer coefficients calculated by Equations (10) and (18).

\begin{tabular}{cccccc}
\hline $\boldsymbol{q}^{\mathbf{}}\left(\mathbf{k W} / \mathbf{m}^{\mathbf{2}}\right)$ & $\mathbf{9 . 2 4}$ & $\mathbf{1 1 . 1 3}$ & $\mathbf{1 3 . 3 0}$ & $\mathbf{1 5 . 9 8}$ & $\mathbf{1 8 . 3 3}$ \\
\hline Equation (10) & $15.4 \%$ & $16.5 \%$ & $14.1 \%$ & $13.5 \%$ & $14.2 \%$ \\
Equation $(18)$ & $7.1 \%$ & $7.5 \%$ & $4.9 \%$ & $6.8 \%$ & $3.5 \%$ \\
\hline
\end{tabular}

Based on the data shown in Table 4, it was observed that the MREs took lower values for the one-dimensional approach. Generally, the MRE decreased when the heat flux $q^{\prime \prime}$ supplied to the cartridge heater increased.

\section{Conclusions}

The results of flow boiling heat transfer in an annular minigap were presented. The working fluid circulated in a flow loop was HFE-649. The essential element of the experimental stand was a test section with a minigap of $2 \mathrm{~mm}$ width, vertically oriented. During the experimental series, heat flux supplied to the heater was increased. It was assumed the laminar fluid flow and the steady-state heat transfer process. Thermocouples were used to measure the temperature of the heater and fluid at the inlet and the outlet to the minigap.

The paper proposed a mathematical model of heat transfer in flow boiling in a minigap. The use of known harmonic functions and T-functions for energy equations with constant velocity allowed to compute two-dimensional temperature distributions in the copper pipe and flowing liquid and then, based on the third kind boundary condition, the heat transfer coefficient at the heater-fluid interface. The results were presented as two-dimensional fields of heater and flowing fluid temperatures and heat transfer coefficients versus the distance from the minigap inlet.

Based on the results from the experiments carried out and the numerical analysis, the following conclusions can be drawn:

- The heat transfer coefficient values decreased along the entire heater length of the minigap in the analyzed saturated boiling region, which resulted from the increase of the vapor phase in the flow;

- The heat transfer coefficient calculated from both mathematical approaches were similar, as evidenced by the MRD. Larger MRD values were obtained for lower values of the heat flux;

- The uncertainty analysis indicated that MRE values determined from the two-dimensional approach were higher than MREs for the one-dimensional approach. MREs decreased with the increase of the heat flux, regardless of the method for determining the transfer coefficient; and

- It should be noted that using the Trefftz method is convenient because it yields solutions thatdo satisfy the governing equation exactly. This method allows solving both direct and inverse heat conduction problems.

Further extended research on an improved experimental stand is planned. Having more results of wider ranges of thermal-flow parameters will allow for their reliable comparison with the correlations reported in the literature.

Author Contributions: Methodology, S.H., Investigation, M.P., the remaining roles: both authors have contributed equally. All authors have read and agreed to the published version of the manuscript.

Funding: This research was funded partially by the Poland National Science Centre; grant number UMO-2018/31/B/ST8/01199.

Conflicts of Interest: The authors declare no conflict of interest. 


\section{Nomenclature}

\begin{tabular}{|c|c|}
\hline$a$ & thermal diffusivity, $\mathrm{m}^{2} / \mathrm{s}$ \\
\hline$a_{n}, b_{n}, c_{n}$ & coefficients \\
\hline$c_{p}$ & specific heat capacity, J/(kg K) \\
\hline$f_{n, 0}$ & T-functions \\
\hline$f_{n, \mathrm{i}}$ & polynomials \\
\hline$g$ & T-function \\
\hline$h$ & heat transfer coefficient, $\mathrm{W} /\left(\mathrm{m}^{2} \mathrm{~K}\right)$ \\
\hline$I$ & current, A \\
\hline$J$ & functional \\
\hline$k$ & thermal conductivity, $\mathrm{W} /(\mathrm{m} \mathrm{K})$ \\
\hline$L$ & length of a minigap, $\mathrm{m}$ \\
\hline$N$ & number of T-functions \\
\hline$M$ & number of T-functions \\
\hline MRE & mean relative error \\
\hline MRD & maximum relative differences \\
\hline MSE & mean square error \\
\hline$r$ & radius, $\mathrm{m}$ \\
\hline$p$ & pressure, $\mathrm{hPa}$ \\
\hline$q^{\prime \prime}$ & heat flux, $\mathrm{W} / \mathrm{m}^{2}$ \\
\hline$T$ & temperature, $\mathrm{K}$ \\
\hline$\Delta U$ & voltage drop, $\mathrm{V}$ \\
\hline$u$ & T-function \\
\hline$v$ & velocity, m/s \\
\hline$z$ & coordinate, $\mathrm{m}$ \\
\hline \multicolumn{2}{|c|}{ Greek Symbols } \\
\hline$\Delta^{-1}$ & inverse Laplacian \\
\hline$\rho$ & density, $\mathrm{kg} / \mathrm{m}^{3}$ \\
\hline \multicolumn{2}{|c|}{ Subscripts } \\
\hline approx & approximation \\
\hline ave & average \\
\hline$c p$ & copper pipe \\
\hline$f$ & fluid \\
\hline in & inlet \\
\hline out & outlet \\
\hline sat & saturation \\
\hline 1D & one-dimensional approach \\
\hline $2 \mathrm{D}$ & two-dimensional approach \\
\hline
\end{tabular}

\section{References}

1. Piasecka, M. Laser texturing, spark erosion and sanding of the surfaces and their practical applications in heat exchange devices. Adv. Mater. Res. 2014, 874, 95-100. [CrossRef]

2. Li, Q.; Flamant, G.; Yuana, X.; Neveub, P.; Luod, L. Compact heat exchangers: A review and future applications for a new generation of high temperature solar receivers. Renew. Sustain. Energy Rev. 2011, 15, 4855-4875. [CrossRef]

3. Boye, G.; Schmidt, G.J.; Beyrau, F. Analysis of flow boiling heat transfer in narrow annular gaps applying the design of experiments method. Adv. Mech. Eng. 2015, 7, 1-14. [CrossRef]

4. Yin, C.P.; Yan, Y.Y.; Lin, T.F.; Yang, B.C. Subcooled flow boiling heat transfer of R-134a and bubble characteristics in a horizontal annular duct. Int. J. Heat Mass Transf. 2000, 43, 1885-1896. [CrossRef]

5. Hsieh, F.C.; Li, K.W.; Lie, Y.M.; Chen, C.A.; Lin, T.F. Saturated flow boiling heat transfer of R-407C and associated bubble characteristics in a narrow annular duct. Int. J. Heat Mass Transf. 2008, 51, 3763-3775. [CrossRef] 
6. Chen, C.A.; Chang, W.R.; Li, K.W.; Lie, Y.M.; Lin, T.F. Subcooled flow boiling heat transfer of R-407C and associated bubble characteristics in a narrow annular duct. Int. J. Heat Mass Transf. 2009, 52, 3147-3158. [CrossRef]

7. Hożejowska, S.; Musiał, T.; Piasecka, M. Heat transfer coefficient for flow boiling in an annular mini gap. EPJ Web Conf. 2016, 114, 1-6. [CrossRef]

8. Piasecka, M.; Hożejowska, S.; Musiał, T. Modelling of flow boiling heat transfer in a cylindrical annulus gap. E3S Web Conf. 2017, 13, 1-4. [CrossRef]

9. Piasecka, M.; Musiał, T.; Piasecki, A. Cooling liquid flow boiling heat transfer in an annular minigap with an enhanced wall. EPJ Web Conf. 2019, 213, 1-8. [CrossRef]

10. Hożejowska, S.; Piasecka, M. The application of Fourier transform to the identification of temperature distribution in HFE-7100 flow boiling in an annular minigap. MATEC Web Conf. 2018, 240, 1-5. [CrossRef]

11. Maciejewska, B.; Piasecka, M. An application of the non-continuous Trefftz method to the determination of heat transfer coefficient for flow boiling in a minichannel. Heat Mass Transf. 2017, 53, 1211-1224. [CrossRef]

12. Maciejewska, B.; Piasecka, M. Trefftz function-based thermal solution of inverse problem in unsteady-state flow boiling heat transfer in a minichannel. Int. J. Heat Mass Transf. 2017, 107, 925-933. [CrossRef]

13. Strak, K.; Piasecka, M.; Maciejewska, B. Spatial orientation as a factor in flow boiling heat transfer of cooling liquids in enhanced surface minichannels. Int. J. Heat Mass Transf. 2018, 117, 375-387. [CrossRef]

14. Maciejewska, B.; Strąk, K.; Piasecka, M. The solution of a two-dimensional inverse heat transfer problem using the Trefftz method. Procedia Eng. 2016, 157, 82-88. [CrossRef]

15. Hożejowska, S.; Piasecka, M.; Piasecki, A. Trefftz method in solving Fourier-Kirchhoff equation for two-phase flow boiling in a vertical rectangular minichannel. EPJ Web Conf. 2017, 143, 1-4. [CrossRef]

16. Hożejowska, S.; Kaniowski, R.; Poniewski, M.E. Experimental investigations and numerical modeling of 2D temperature fields in flow boiling in minichannels. Exp. Therm. Fluid Sci. 2016, 78, 18-29. [CrossRef]

17. Orman, Ł.J.; Radek, N.; Kapjor, A. Surface treatment technologies for boiling heat transfer augmentation. Mater. Res. Proc. 2018, 5, 216-219. [CrossRef]

18. Orman, Ł.J.; Radek, N.; Broncek, J. Sintered mesh layers for the production of efficient phase-Change heat exchangers. Mater. Res. Proc. 2018, 5, 189-193. [CrossRef]

19. Bochnia, J.; Blasiak, S. Fractional relaxation model of materials obtained with selective laser sintering technology. Rapid Prototyp. J. 2019, 25, 78-86. [CrossRef]

20. Ozisik, M.N.; Orlande, H.R.B. Inverse Heat Transfer: Fundamentals and Applications, 1st ed.; Taylor \& Francis: New York, NY, USA, 2000.

21. Beck, J.V.; Woodbury, K.A. Inverse heat conduction problem: Sensitivity coefficient insights, filter coefficients and intrinsic verification. Int. J. Heat Mass Transf. 2016, 97, 578-588. [CrossRef]

22. Colaco, M.J.; Orlande, H.B.R.; Dulikravich, G.S. Inverse and optimization problems in heat transfer. J. Braz. Soc. Mech. Sci. Eng. 2006, 28, 1-24. [CrossRef]

23. Chang, C.-W.; Liu, C.-H.; Wang, C.-C. Review of computational schemes in inverse heat conduction problems. Smart Sci. 2018, 8, 94-103. [CrossRef]

24. Sharma, D.; Parwani, A.K.; Shrivastava, C. A review on solution of inverse heat conduction problems. Int. J. Eng. Res. Technol. 2014, 3, 1955-1958.

25. Guo, Z.; Fletcher, D.F.; Haynes, B.S. A review of computational modelling of flow boiling in microchannels. J. Comput. Mult. Flows 2014, 6, 79-110. [CrossRef]

26. Grysa, K.; Maciagg, A.; Pawińska, A. Solving nonlinear direct and inverse problems of stationary heat transfer by using Trefftz functions. Int. J. Heat Mass Transf. 2012, 55, 7336-7340. [CrossRef]

27. Grysa, K.; Maciagg, A.; Cebo-Rudnicka, A.; Walaszczyk, M. Identification of the heat transfer coefficient during cooling process by means of Trefftz method. Eng. Anal. Bound. Elem. 2018, 95, 33-39. [CrossRef]

28. Hadamard, J. Sur Les Problèmes Aux DérivéesPartielles Et Leur Signification Physique; Princeton University Bulletin: Princeton, NJ, USA, 1902; pp. 49-52.

29. Trefftz, E. Ein Gegenstück zum Ritzschen Verfahren; 2 Int; Kongress für Technische Mechanik: Zürich, Switzerland, 1926; pp. 131-137.

30. Grabowski, M.; Hożejowska, S.; Pawińska, A.; Poniewski, M.E.; Wernik, J. Heat transfer coefficient identification in minichannel flow boiling with hybrid Picard-Trefftz method. Energies 2018, 11, 2057. [CrossRef] 
31. Hożejowska, S.; Hożejowski, L. Trefftz method in an inverse problem of two-phase flow boiling in a minichannel. Eng. Anal. Bound. Elem. 2019, 98, 27-34. [CrossRef]

32. Herrera, I. Trefftz method: A general theory. Numer. Meth Partial Differ. Equ. Int. J. 2000, 16, 561-580. [CrossRef]

33. Kita, E.; Kamiya, N. Trefftz method: An overview. Adv. Eng. Softw. 1995, 24, 3-12. [CrossRef]

34. Zielinski, A.P. On trial functions applied in the generalized Trefftz method. Adv. Eng. Softw. 1995, 24, 147-155. [CrossRef]

35. Hożejowska, S. Determining 2D temperature field in flow boiling with the use of Trefftz functions. EPJ Web Conf. 2019, 213, 1-6. [CrossRef]

(C) 2020 by the authors. Licensee MDPI, Basel, Switzerland. This article is an open access article distributed under the terms and conditions of the Creative Commons Attribution (CC BY) license (http://creativecommons.org/licenses/by/4.0/). 